\title{
The use of NMR spectroscopy to probe chemical environment surrounding intracellular amorphous carbonates formed by cyanobacteria
}

\author{
NEHA MEHTA ${ }^{1}$, TRISTAN GEORGES ${ }^{2}$, THIERRY AZAÏS ${ }^{2}$, \\ GUILLAUME P LAURENT ${ }^{2}$, CRISTINA COELHO-DIOGO ${ }^{2}$ \\ AND KARIM BENZERARA ${ }^{3}$ \\ ${ }^{1}$ Sorbonne University \\ ${ }^{2}$ Sorbonne Université \\ ${ }^{3}$ IMPMC, CNRS, Sorbonne Université, MNHN \\ Presenting Author: neha.mehta@upmc.fr
}

Cyanobacteria are phylogenetically and ecologically diverse photosynthetic bacteria, playing a central role in the global cycling of numerous elements. Several species were shown to form intracellular amorphous calcium carbonates (iACC), containing high quantities of alkaline earth elements, including $\mathrm{Ca}$ but also $\mathrm{Sr}$ or $\mathrm{Ba}$ [1-2]. While this has implications for geochemical cycling of these elements, it also questions how metastable phases such as amorphous carbonates are stabilized in these systems. Numerous organic and inorganic additives have been shown to perform this role, but the mechanisms yet remain elusive. Novel tools are necessary to identify exactly how these additives interact at the organic-mineral interface. Solid-state NMR spectroscopy (ssNMR) is one of such tools to explore the local molecular environment surrounding the organic-mineral interface [3]. Here, we present an application of ssNMR spectroscopy to characterize the chemical environment of $\mathrm{CO}_{3}{ }^{2-}$, $\mathrm{Ca}^{2+}$ and $\mathrm{Sr}^{2+}$ within iACC of cyanobacteria. The originality of our approach lies in studying intact cells without any prior treatment, which helps preserving intracellular amorphous phases, that are otherwise unstable. Both $\mathrm{Ca}$ and $\mathrm{Sr}$ active nuclei $\left({ }^{43} \mathrm{Ca}\right.$ and $\left.{ }^{87} \mathrm{Sr}\right)$ are challenging for NMR studies owing to their intrinsic low sensitivity. To address this shortcoming, we labelled the growth media using the NMR-active ${ }^{43} \mathrm{Ca},{ }^{87} \mathrm{Sr}$ and ${ }^{13} \mathrm{C}$ isotopes that were incorporated by the cyanobacteria and allowed to study their speciation and the structure at atomic level. Preliminary results clearly identified ACC by its carbonate resonance at $169 \mathrm{ppm}$ in ${ }^{13} \mathrm{C}$-cross polarization (CP) spectrum of the intact cyanobacteria cell. Based on $2 \mathrm{D}{ }^{1} \mathrm{H}-{ }^{13} \mathrm{C} \quad \mathrm{NMR}$ experiments, we will also describe the chemical environment of the proton and carbon in proximity to ACC. Lastly, we will discuss the ongoing investigation, describing the $\mathrm{Ca}^{2+}$ and $\mathrm{Sr}^{2+}$ environment in iACC using ${ }^{87} \mathrm{Sr}$-ssNMR and ${ }^{43} \mathrm{Ca}-\mathrm{ssNMR}$. Altogether, this study will reveal the first clues about the local structure of $\mathrm{C}, \mathrm{Ca}$ and $\mathrm{Sr}$ within iACC formed by cyanobacteria and shed light into underlying mechanisms of biologically controlled biomineralization.

[1] Mehta et al. (2019), Environ. Sci. Technol. 53, 1263912647.

[2] Benzerara et al. (2014) Proc. Natl. Acad. Sci. USA 111, 10933-10938.

[3] Cartwright et al. (2012) Angewandte Chemie, 51, 11960- 